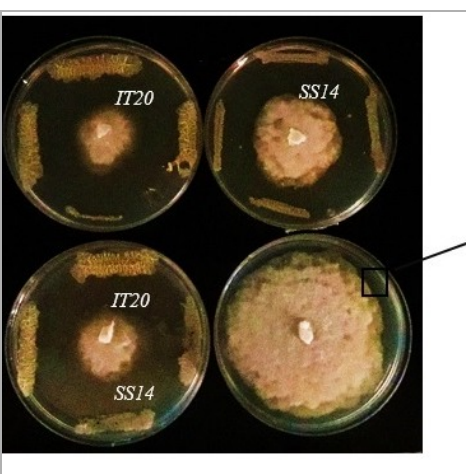

DOI:

dx.doi.org/10.17504/protocol s.io.bcbyispw

Protocol Citation: Sakineh Abbasi . screen of antioomycete strains of Streptomyces. protocols.io https://dx.doi.org/10.17504/p rotocols. io. bcbyispw

License: This is an open access protocol distributed under the terms of the Creative Commons Attribution License, which permits unrestricted use, distribution, and reproduction in any medium, provided the original author and source are credited

Created: Feb 09, 2020

Last Modified: Feb 09, 2020

PROTOCOL integer ID: 32856

\section{(-) screen of anti-oomycete strains of Streptomyces}

Sakineh $\mathrm{Abbasi}^{1}$

${ }^{1}$ Tarbiat Modares University

Sakineh Abbasi

\section{ABSTRACT}

the inhibition of mycelial growth and germination of Phytophthora capsiciafter six days of incubation by Streptomyces strains 